\title{
Comparison of clinicopathological features and treatments between pre- and postmenopausal female breast cancer patients - a retrospective study
}

\author{
Servet Kocaöz ${ }^{1}$, Birol Korukluoğlu¹, Ömer Parlak², Hayriye Tatı Doğan³, Fazlı Erdoğan³ \\ ${ }^{1}$ Department of General Surgery, Ankara Atatürk Training and Research Hospital, Bilkent, Ankara, Turkey \\ ${ }^{2}$ Department of General Surgery, Faculty of Medicine, Ankara Yıldırım Beyazıt University, Bilkent, Ankara, Turkey \\ ${ }^{3}$ Department of Medical Pathology, Faculty of Medicine, Ankara Yıldırım Beyazıt University, Bilkent, Ankara, Turkey
}

\begin{abstract}
Introduction: To find out if there are clinical and biological differences in breast cancer characteristics of premenopausal and postmenopausal women. For this reason, we investigated the differences in terms of the clinicopathological features and treatment methods of premenopausal and postmenopausal breast cancer patients in our study.

Material and methods: In this study, the files of 428 patients who were operated due to breast cancer between 1 January 2007 and 31 December 2017 in Ankara Atatürk Training and Research Hospital were examined retrospectively. The age, tumour size, tumour grade, oestrogen receptor, progesterone receptor, HER2 score, Ki-67 proliferation index, perineural invasion, and lymphovascular invasion were investigated.

Results: In patients with premenopausal breast cancer, the tumour diameter was larger $(p=0.047)$ and the lymph node metastasis was higher $(p<0.001)$. Oestrogen receptor $(\mathrm{OR})$ expression $(p=0.002)$, progesterone receptor (PR) expression ( $p=0.014$ ), negative human epidermal growth factor receptor 2 (HER2) expression $(p=0.038)$, and $\mathrm{Ki}-67$ expression $(p=0.017)$ were higher in the premenopausal group. In the premenopausal group, breast conserving surgery $(p=0.004)$, chemotherapy $(p=0.007)$, radiotherapy $(p=0.008)$, and endocrine therapy $(p=0.025)$ were higher than in the postmenopausal group.

Conclusions: Premenopausal and postmenopausal female breast cancer patients have significant differences in tumour size, tumour grade, axillary lymph node metastasis, hormone receptor status, HER2 expression, and treatment modalities.
\end{abstract}

Key words: breast cancer, hormone receptor, premenopausal, postmenopausal, breast-conserving surgery.

\section{Introduction}

In recent years, the incidence of breast cancer has increased all over the world. In 2012, the incidence of breast cancer in Asian countries was reported as 27 per 100,000 women and 92 per 100,000 women in the United States [1]. The incidence of breast cancer in Turkey was 31.9 per 100,000 in 2002, and 43 per 100,000 in 2014. The most common type of cancer among women in Turkey, seen with a rate of $24.9 \%$, is breast cancer [2]. According to the World Health Organisation, in 2016 the incidence of breast cancer was 1.7 million and resulted in 535,000 deaths worldwide [3]. Breast cancer diagnosis is recommended by breast self-examination, ultrasonography (USG), and mammography. Factors such as prolonged exposure to the oestrogen effect (early menarche, nulliparity, and late menopause), older age at first live birth, obesity, alcohol use, and long-term consumption of high-fat diets increase serum oestrogen levels and increase breast cancer risk [4-6]. Exposure to radiation also increases breast cancer risk [7]. Factors protecting from breast cancer include short duration of oestrogen effect, moderate exercise, longer lactation duration, and breastfeeding [8]. The protective effect of multiparity decreases along with postmenopausal breast cancer; breastfeeding is an important factor in reducing the risk of breast cancer in the postmenopausal period [9].

The age of menopause varies between the ages of 45 and 55 years in Turkey. The mean age is $47 \pm 4.2$ years [10]. There are clinical and biological differences in patients with premenopausal and postmenopausal breast cancer. Premenopausal tumours peak in early life whereas postmenopausal tumours peak in later life [11]. It is estimated that the incidence of hormone receptor-positive breast cancer is affected by the menopausal transition [12]. Immunohistochemical status of 
oestrogen receptors (OR), progesterone receptors (PR), and human epidermal growth factor receptor 2 (HER2) are among the factors that influence breast cancer treatment options and prognosis $[13,14]$. There is an inverse relationship between $\mathrm{OR}, \mathrm{PR}$ expression, and Ki-67 mitotic proliferation index [15]. OR, PR, HER2 receptor level, Ki-67 proliferation index, and some risk factors also determine treatment selection and prognosis [16]. Although there are studies reporting that breast cancer hormone receptors are affected by menopause, there are still discussions about this subject. Therefore, whether premenopausal and postmenopausal patients with breast cancer may differ between clinicopathological features and treatment modalities should be investigated.

The aim of this study is to develop treatment strategies, to improve the prognosis of patients, and to gain valuable insights into the effects of menopause. For this reason, we compared the differences between premenopausal breast cancer patients and postmenopausal patients in terms of clinicopathologic features and treatment methods.

\section{Material and methods}

The files of 428 patients who underwent surgery for breast cancer between January 1, 2007 and December 31, 2017 were reviewed retrospectively in the Atatürk Training and Research Hospital. Age of the patients, type of surgery, lateralisation of the tumour, and pathology report were obtained from the archive. Preoperative and postoperative laboratory examinations, pathological examination results, oestrogen and progesterone receptor positivity grade, HER2, and $\mathrm{Ki}-67$ status were retrospectively recorded from the HBYS program. Tumour location, differentiation grade, lymphovascular invasion, perineural invasion, and lymph node metastasis, the patients' treatment regimens, surgical types, and axillary lymph node dissection procedures, follow-up protocols of patients, whether the cancer is recurrent or not, and five-year survival periods were also recorded.

\section{Ethical consideration}

The study was commenced after obtaining written consent from the Yıldırım Beyazıt University Medical Faculty Clinical Research Ethical Evaluation Commission (decision no. 191, 11 July 2018) at the hospital where the study would be conducted.

\section{Statistical analysis}

The data obtained from the study were evaluated in the SPSS program (version 25.0; SPSS, Chicago, IL,
USA). In the evaluation of descriptive statistics, number, percentage, mean, standard deviation values were used. The differences in the demographic, clinical, and pathological characteristics and in treatments between the two groups were analysed using Student's t-test in the case of quantitative variables and $\chi^{2}$ tests in the case of categorical variables.

\section{Results}

In our study, the mean age of the patients during diagnosis of breast cancer was $56.16 \pm 12.71$ years, the mean age of the premenopausal patients was 46.84 \pm 6.44 years (minimal age: 19 years, maximal age: 55 years), and the mean age of the postmenopausal patients was $66.02 \pm 9.96$ years (minimal age: 44 years, maximal age: 96 years). Premenopausal patients between 47-52 years of age and postmenopausal patients were between 58-65 years of age were found to develop a breast cancer peak.

There was no significant difference between the groups in terms of tumour histology $(p=0.795)$ (Table 1). In $22.55 \%$ of the premenopausal patients, the tumour diameter was $<2 \mathrm{~cm}$, in $56.17 \%$ the tumour diameter was $2-5 \mathrm{~cm}$, and in $21.28 \%$ of the patients the tumour size was greater than $5 \mathrm{~cm}$. In postmenopausal patients these figures were, respectively, $22.8 \%$, $64.77 \%$, and $12.43 \%$. In premenopausal patients, the number of patients with tumor diameter greater than $5 \mathrm{~cm}$ was significantly higher than postmenopausal patients $(p=0.047)$. The axillary lymph node in $76.60 \%$ of premenopausal patients and in $57.51 \%$ of postmenopausal patients was positive. Lymph node involvement was significantly higher in the premenopausal group $(p<0.001)$.

We found that patients in the premenopausal group had a higher likelihood of positive expression of OR than patients in the postmenopausal group (55.8\% vs. $44.2 \%, p=0.002$ ). For patients in the premenopausal group PR was more likely to show positive expression than for those in the postmenopausal group $(52.7 \%$ vs. $40.9 \%, p=0.014)$. It was also found that the probability of OR and PR showing double positive expression in the premenopausal group (Table 2) was higher than in the postmenopausal group (53.61\% vs. $30.05 \%$, $p<0.0001)$. OR+ and PR- were significantly higher in the postmenopausal group than in the premenopausal group (15.32\% vs. $24.87 \% p=0.013)$. Similarly, OR- and PR+ were significantly higher in the postmenopausal group than in the premenopausal group ( $4.25 \%$ vs. $12.95 \%, p=0.001)$. OR- and PR- were found to be significantly higher in the postmenopausal group than in the premenopausal group (28.08\% vs. $43 \%$, $p<0.001$ ). HER2 positivity was significantly higher in the postmenopausal group than in the group premenopausal $(11.91 \%$ vs. $19.17 \% p=0.038)$. Ki67 expression 
Table 1. Pathological characteristics of the tumours

\begin{tabular}{|c|c|c|c|c|c|c|c|}
\hline \multirow[t]{2}{*}{ Characteristics } & \multicolumn{2}{|c|}{ Premenopausal } & \multicolumn{2}{|c|}{ Postmenopausal } & \multicolumn{2}{|c|}{ Total } & \multirow[t]{2}{*}{$p$-value } \\
\hline & $n$ & $\%$ & $n$ & $\%$ & $n$ & $\%$ & \\
\hline \multicolumn{8}{|l|}{ Tumour histology } \\
\hline Carcinoma in situ & 7 & 2.98 & 7 & 3.63 & 14 & 3.27 & 0.795 \\
\hline Invasive carcinoma & 211 & 89.79 & 172 & 89.12 & 383 & 89.49 & \\
\hline Other carcinomas & 17 & 7.23 & 14 & 7.25 & 31 & 7.24 & \\
\hline \multicolumn{8}{|l|}{ Tumour size } \\
\hline$<2 \mathrm{~cm}$ & 53 & 22.55 & 44 & 22.80 & 97 & 22.66 & 0.047 \\
\hline $2-5 \mathrm{~cm}$ & 132 & 56.17 & 125 & 64.77 & 257 & 60.05 & \\
\hline$>5 \mathrm{~cm}$ & 50 & 21.28 & 24 & 12.43 & 74 & 17.29 & \\
\hline \multicolumn{8}{|c|}{ Axillary lymph nodes metastasis } \\
\hline Negative & 55 & 23.40 & 82 & 42.49 & 137 & 32.01 & $<0.001$ \\
\hline Positive & 180 & 76.60 & 111 & 57.51 & 291 & 67.99 & \\
\hline \multicolumn{8}{|l|}{ Tumour grade } \\
\hline 1 & 26 & 11.06 & 41 & 21.24 & 67 & 15.65 & 0.001 \\
\hline II & 120 & 51.06 & 105 & 54.40 & 225 & 52.57 & \\
\hline III & 89 & 37.87 & 47 & 24.35 & 136 & 31.78 & \\
\hline
\end{tabular}

Table 2. Immunohistochemical marker characteristics of the tumours

\begin{tabular}{|c|c|c|c|c|c|c|c|}
\hline \multirow[t]{2}{*}{ Characteristics } & \multicolumn{2}{|c|}{ Premenopausal } & \multicolumn{2}{|c|}{ Postmenopausal } & \multicolumn{2}{|c|}{ Total } & \multirow[t]{2}{*}{$p$-value } \\
\hline & $n$ & $\%$ & $n$ & $\%$ & $n$ & $\%$ & \\
\hline \multicolumn{8}{|l|}{$\mathrm{OR}+/ \mathrm{PR}+$} \\
\hline Yes & 126 & 53.61 & 58 & 30.05 & 184 & 42.99 & \multirow[t]{2}{*}{$<0.001$} \\
\hline No & 109 & 46.39 & 135 & 69.95 & 244 & 57.01 & \\
\hline \multicolumn{8}{|l|}{$\mathrm{OR}+/ \mathrm{PR}-$} \\
\hline Yes & 36 & 15.32 & 48 & 24.87 & 84 & 19.63 & \multirow[t]{2}{*}{0.013} \\
\hline No & 199 & 84.68 & 145 & 75.13 & 344 & 80.37 & \\
\hline \multicolumn{8}{|l|}{ OR-/PR+ } \\
\hline Yes & 10 & 4.25 & 25 & 12.95 & 35 & 8.18 & \multirow[t]{2}{*}{0.001} \\
\hline No & 225 & 95.75 & 168 & 87.05 & 393 & 91.82 & \\
\hline \multicolumn{8}{|l|}{ OR-/PR- } \\
\hline Yes & 66 & 28.08 & 83 & 43.01 & 149 & 34.81 & \multirow[t]{2}{*}{0.001} \\
\hline No & 169 & 71.92 & 110 & 56.99 & 279 & 65.19 & \\
\hline \multicolumn{8}{|l|}{ HER2+ } \\
\hline Yes & 28 & 11.91 & 37 & 19.17 & 65 & 15.19 & \multirow[t]{2}{*}{0.038} \\
\hline No & 207 & 88.09 & 156 & 80.83 & 363 & 84.81 & \\
\hline \multicolumn{8}{|l|}{ Triple negative } \\
\hline Yes & 51 & 21.7 & 42 & 21.76 & 93 & 21.73 & \multirow[t]{2}{*}{0.988} \\
\hline No & 184 & 78.3 & 151 & 78.24 & 335 & 78.27 & \\
\hline \multicolumn{8}{|l|}{ Ki-67+ } \\
\hline Yes & 78 & 33.19 & 44 & 22.8 & 122 & 28.5 & \multirow[t]{2}{*}{0.017} \\
\hline No & 157 & 66.81 & 149 & 77.2 & 306 & 71.5 & \\
\hline
\end{tabular}

was significantly higher in the premenopausal group than in the postmenopausal group (33.19\% vs. $22.8 \%$, $p=0.017$ ).

Chemotherapy, radiotherapy, and endocrine therapy for the premenopausal disease were more frequent- ly performed (Table 3). Chemotherapy treatment was found to be higher in the premenopausal group than in the postmenopausal group (83.83\% vs. $73.06 \%$, $p=0.007)$. Radiotherapy was used more frequently in the premenopausal group than in the postmenopausal 
Table 3. Treatments of the patients with breast cancer

\begin{tabular}{|c|c|c|c|c|c|c|c|}
\hline \multirow[t]{2}{*}{ Characteristics } & \multicolumn{2}{|c|}{ Premenopausal } & \multicolumn{2}{|c|}{ Postmenopausal } & \multicolumn{2}{|c|}{ Total } & \multirow[t]{2}{*}{$p$-value } \\
\hline & $n$ & $\%$ & $n$ & $\%$ & $n$ & $\%$ & \\
\hline \multicolumn{8}{|l|}{ Chemotherapy } \\
\hline Yes & 197 & 83.83 & 141 & 73.06 & 338 & 78.97 & 0.007 \\
\hline No & 38 & 16.17 & 52 & 26.94 & 90 & 21.03 & \\
\hline \multicolumn{8}{|l|}{ Radiotherapy } \\
\hline Yes & 53 & 22.55 & 26 & 13.47 & 79 & 18.46 & 0.008 \\
\hline No & 182 & 77.45 & 167 & 86.53 & 317 & 81.54 & \\
\hline \multicolumn{8}{|l|}{ Endocrine therapy } \\
\hline Yes & 71 & 30.21 & 40 & 20.73 & 111 & 25.93 & 0.025 \\
\hline No & 164 & 69.79 & 153 & 79.27 & 317 & 74.07 & \\
\hline \multicolumn{8}{|l|}{ Anti-HER2 therapy } \\
\hline Yes & 19 & 8.09 & 9 & 4.66 & 28 & 6.54 & 0.149 \\
\hline No & 216 & 91.91 & 184 & 95.34 & 400 & 93.46 & \\
\hline \multicolumn{8}{|l|}{ Type of surgery } \\
\hline $\begin{array}{l}\text { Type of surgery modified } \\
\text { Radical mastectomy }\end{array}$ & 183 & 77.87 & 147 & 76.17 & 330 & 77.10 & 0.004 \\
\hline Breast-conserving surgery & 22 & 9.36 & 6 & 3.11 & 28 & 6.54 & \\
\hline Simple mastectomy and other & 30 & 12.77 & 40 & 20.72 & 70 & 16.36 & \\
\hline
\end{tabular}
$\chi^{2}$ test

group $(22.55 \%$ vs. $13.47 \%, p=0.008)$. Endocrine therapy was used more frequently in the premenopausal group than in the postmenopausal group (30.21\% vs. $20.73 \%, p<0.025)$. There was no significant difference in anti-HER2 treatment ( $8.09 \%$ vs. $4.66 \%, p=0.149$ ). Breast-conserving surgery was performed more frequently in the premenopausal group (9.36\% vs. 3.11\%, $p=0.004$ ). While $90 \%$ of premenopausal patients undergoing breast-conserving surgery completed their five-year lifespan, $88 \%$ of postmenopausal patients completed their five-year lifespan.

\section{Discussion}

Differences in some risk factors between premenopausal women with breast cancer and postmenopausal women were identified. Patients with premenopausal breast cancer constituted $54.9 \%$ of all patients in our study. Similar rates were found in studies conducted in Asia, at 54.3-54.55\% [17, 18].

We found the mean age of the patients with breast cancer to be $58 \pm 12.69$ years in our study. Age is an important factor affecting breast cancer development. Younger women have been reported to have larger breast cancer tumour size, higher HER-2/EGFR expression, and worse prognosis $[19,20]$. In our study, the number of patients with breast cancer greater than $5 \mathrm{~cm}$ was higher in the premenopausal group. In addition, HER-2 expression in the premenopausal group was higher than in the postmenopausal group. Young premenopausal women have been reported to have a larger breast tumour di- ameter, higher-grade breast cancer, and more negative tumour receptors [21]. In our study, in patients with premenopausal breast cancer, the number of patients with a tumour diameter greater than $5 \mathrm{~cm}$ was found to be higher than in the postmenopausal group. In premenopausal patients, tumour grade was higher than in the postmenopausal group. The OR-PR receptor status is the most important indication that will guide endocrine treatment to be administered to the patient. It is also an important factor that affects the prognosis of breast cancer $[22,23]$. In our study, OR positivity was high in both premenopausal women and postmenopausal women. OR positivity was $68.94 \%$ in the premenopausal group and $54.92 \%$ in the postmenopausal group; Feng et al. found $59 \%$ in the premenopausal group and 55\% in the postmenopausal group in their study [17]. In the premenopausal group, $\mathrm{OR}+\mathrm{PR}+$ patients were at a higher rate, whereas in the postmenopausal group OR- PRpatients were higher. There was a negative correlation between OR+ expression and overexpression of HER-2. $\mathrm{OR}+$ has been reported to be associated with a better prognosis [24]. We achieved similar results in our study. In our study, $97 \%$ of premenopausal patients with OR+ and anti-HER2 treatment and $95 \%$ of postmenopausal patients completed five-year survival. Studies have shown that HER2 expression of breast cancer cells in premenopausal women is lower than in postmenopausal women [25-27].

In women with premenopausal breast cancer, axillary lymph node metastasis was significantly higher than in postmenopausal women. The presence of lymph 
node involvement is an important factor in follow-up of breast cancer recurrence [20]. As the surgical approach, the most common technique in both groups was modified radical mastectomy surgery. Breast-conserving surgery was significantly more common in premenopausal woman than in postmenopausal women $(9.36 \%$ vs. $3.11 \%, p=0.004)$. In recent years, sentinel lymph node biopsy has been performed in our clinic during operation. Breast-conserving surgery, simple mastectomy, or modified radical mastectomy have been performed according to the results. After a simple mastectomy and breast-conserving operations, axillary lymph node dissection was performed. Mastectomy and breast-conserving operations were reported as $87.6 \%$ and $93.2 \%$, respectively, in five-year recurrence-free survival studies [28]. Chemotherapy was used more in the premenopausal group because the risk of tumour recurrence is higher in patients with premenopausal breast cancer. It has been reported that chemotherapy is the most widely used adjuvant therapy in breast cancer treatment, and it significantly reduces the risk of breast cancer recurrence [22]. LHRH agonists or laparoscopic bilateral salpingo-oophorectomy are recommended for the treatment of breast cancer patients who are premenopausal hormone receptor positive and 40-49 years old [29]. Postoperative adjuvant radiotherapy decreases local recurrence and increases the survival rate in patients who have undergone breast-conserving surgery or who have had lymph node involvement after mastectomy [30].

\section{Conclusions}

In conclusion, premenopausal and postmenopausal female breast cancer patients have significant differences in tumour size, tumour grade, axillary lymph node metastasis, hormone receptor status, HER2 expression, and treatment modalities. Breast cancer is larger in premenopausal women and tends to develop lymph node metastasis. Chemotherapy, endocrine therapy, and radiotherapy treatments are used more frequently than in postmenopausal women.

\section{Disclosure}

The authors report no conflict of interest.

\section{References}

1. DeSantis CE, Bray F, Ferlay J, et al. International Variation in Female Breast Cancer Incidence and Mortality Rates. Cancer Epidemiol Biomarkers Prev 2015; 24: 1495-1506.

2. Köse MR, Başara BB, Güler C, et al. Republic of Turkey Ministry of Health, Health Statistics Year Book 2016. SB-SAGEM 2017; 4: 37-38.

3. Global Burden of Disease Cancer Collaboration, Fitzmaurice C, Akinyemiju TF, Al Lami FH, et al. Global, Regional, and National Cancer Incidence, Mortality, Years of Life Lost, Years Lived With Disability, and DisabilityAdjusted Life-Years for 29 Cancer Groups, 1990 to 2016: A Systematic
Analysis for the Global Burden of Disease Study. JAMA Oncol 2018; 4 1553-1568.

4. Nattenmüller CJ, Kriegsmann M, Sookthai D, et al. Obesity as risk factor for subtypes of breast cancer: results from a prospective cohort study. BMC Cancer 2018; 18: 616.

5. Singletary SE. Rating the risk factors for breast cancer. Ann Surg 2003; 237: 474-482.

6. Scoccianti C, Cecchini M, Anderson AS, et al. European Code against Cancer 4th Edition: Alcohol drinking and cancer. Cancer Epidemiol 2016; 45: 181-188.

7. Weiderpass $E$, Meo $M$, Vainio $H$. Risk factors for breast cancer, including occupational exposures. Saf Health Work 2011; 2: 1-8.

8. Kruk J. Lifetime physical activity and the risk of breast cancer: a casecontrol study. Cancer Detect Prev 2007; 31: 18-28.

9. Campbell KL, Foster-Schubert KE, Alfano CM, et al. Reduced-calorie dietary weight loss, exercise, and sex hormones in postmenopausa women: randomized controlled trial. J Clin Oncol 2012; 30: 2314-2326.

10. Ozdemir O, Cöl M. The age at menopause and associated factors at the health center area in Ankara, Turkey. Maturitas. 2004; 49: 211-219.

11. Fan L, Strasser-Weippl K, Li JJ, et al. Breast cancer in China. Lancet Oncol 2014; 15: e279-289.

12. Shantakumar S, Terry MB, Teitelbaum SL, et al. Reproductive factors and breast cancer risk among older women. Breast Cancer Res Treat 2007; 102: $365-374$.

13. Tarone RE, Chu KC. The greater impact of menopause on ER- than ER+ breast cancer incidence: a possible explanation (United States). Cancer Causes Control 2002; 13: 7-14.

14. Carey LA, Perou CM, Livasy CA, et al. Race, breast cancer subtypes, and survival in the Carolina Breast Cancer Study. Jama 2006; 295: 2492 2502.

15. Sherman ME, Rimm DL, Yang XR, et al. Variation in breast cancer hormone receptor and HER2 levels by etiologic factors: a population-based analysis. Int J Cancer 2007; 121: 1079-1085.

16. Marwah N, Batra A, Marwah S, et al. Correlation of proliferative index with various clinicopathologic prognostic parameters in primary breast carcinoma: A study from North India. J Cancer Res Ther 2018; 14: 537 542.

17. Feng F, Wei Y, Zheng K, et al. Comparison of epidemiological features, clinicopathological features, and treatments between premenopausal and postmenopausal female breast cancer patients in western China: a retrospective multicenter study of 15,389 female patients. Cancer Med 2018; 7: 2753-2763.

18. Gharaibeh M, Al-Obeisat S, Hattab J. Severity of menopausal symptoms of Jordanian women. Climacteric 2010; 13: 385-394.

19. Anders CK, Hsu DS, Broadwater G, et al. Young age at diagnosis correlates with worse prognosis and defines a subset of breast cancers with shared patterns of gene expression. J Clin Oncol 2008; 26: 3324-3330.

20. Wang K, Ren Y, Li H, et al. Comparison of Clinicopathological Features and Treatments between Young ( $\leq 40$ Years) and Older ( $>40$ Years) Female Breast Cancer Patients in West China: A Retrospective, Epidemiological, Multicenter, Case Only Study. PLoS One 2016; 11: e0152312.

21. Warner ET, Colditz GA, Palmer JR, et al. Reproductive factors and risk of premenopausal breast cancer by age at diagnosis: are there differences before and after age 40? Breast Cancer Res Treat 2013; 142: 165-175.

22. Early Breast Cancer Trialists' Collaborative Group (EBCTCG). Effects of chemotherapy and hormonal therapy for early breast cancer on recurrence and 15-year survival: an overview of the randomised trials. Lancet 2005; 365: 1687-1717.

23. Gao JD, Wang J, Feng XL, et al. Characterization of hormone receptor status in 5758 Chinese females with breast cancer. Zhonghua Zhong Liu Za Zhi 2009; 31: 683-686.

24. Lee A, Park WC, Yim HW, et al. Expression of c-erbB2, cyclin D1 and estrogen receptor and their clinical implications in the invasive ductal carcinoma of the breast. Jpn J Clin Oncol 2007; 37: 708-714.

25. Johnson RH, Hu P, Fan C, Anders CK. Gene expression in ,young adult type" breast cancer: a retrospective analysis. Oncotarget 2015; 6 : 13688-13702.

26. Kheirelseid EH, Boggs JM, Curran C, et al. Younger age as a prognostic indicator in breast cancer: a cohort study. BMC Cancer 2011; 11: 383.

27. Pronzato P, Mustacchi G, De Matteis A, et al. Biological characteristics and medical treatment of breast cancer in young women-a featured 
population: results from the NORA study. Int J Breast Cancer 2011; 2011: 534256

28. Huang NS, Liu MY, Chen JJ, et al. Surgical management of breast cancer in China: A 15 -year single-center retrospective study of 18,502 patients. Medicine (Baltimore) 2016; 95: e4201.

29. Ferrandina G, Amadio G, Marcellusi A, et al. Bilateral Salpingo-Oophorectomy Versus GnRH Analogue in the Adjuvant Treatment of Premenopausal Breast Cancer Patients: Cost-Effectiveness Evaluation of Breast Cancer Outcome, Ovarian Cancer Prevention and Treatment. Clin Drug Investig 2017; 37: 1093-1102.

30. Clarke M, Collins R, Darby S, et al. Effects of radiotherapy and of differences in the extent of surgery for early breast cancer on local recurrence and 15-year survival: an overview of the randomised trials. Lancet 2005; 366: 2087-2106. 